\title{
Evaluation of gastric emptying in patients with gastroparesis by three-dimensional ultrasound
}

\author{
Jinjun Shi ${ }^{1,2 \#}$, Huiming Shen ${ }^{2 \#}$, Qi Gao ${ }^{2}$, Sachin Mulmi Shrestha ${ }^{2}$, Jiacheng Tan $^{3}$, Tong Lu ${ }^{4}$, Bin Yang ${ }^{1}$ \\ ${ }^{1}$ Department of Ultrasound, Jinling Hospital, Nanjing Medical University, Nanjing, China; ${ }^{2}$ Department of Ultrasound, Zhongda Hospital, Medical \\ School, Southeast University, Nanjing, China; ${ }^{3}$ Department of Gastroenterology, Zhongda Hospital, Medical School, Southeast University, Nanjing, \\ China; ${ }^{4}$ Department of Radiology, Zhongda Hospital, Medical School, Southeast University, Nanjing, China \\ Contributions: (I) Conception and design: B Yang; (II) Administrative support: All authors; (III) Provision of study materials or patients: Q Gao; (IV) \\ Collection and assembly of data: All authors; (V) Data analysis and interpretation: All authors; (VI) Manuscript writing: All authors; (VII) Final \\ approval of manuscript: All authors. \\ "These authors contributed equally to this study. \\ Correspondence to: Bin Yang. Department of Ultrasound, Jinling Hospital, Nanjing Medical University, Nanjing, China. Email: yangbin12yx@163.com.
}

Background: To diagnose gastroparesis, it is necessary to assess gastric emptying accurately. This study aims to investigate the role of three-dimensional ultrasonography (3-D US) on the measurement of gastric volume to evaluate gastric accommodation in healthy patients.

Methods: In this study, 21 volunteers, 46 patients with diabetic gastroparesis (DG), and 22 patients with postsurgical gastroparesis (PSG) underwent 3-D US after oral administration of $250 \mathrm{~mL}$ gastrointestinal contrast at 2,30,60, and $90 \mathrm{~min}$. The volume of the contrast agent in the stomach was then calculated using the virtual organ computer-aided analysis (VOCAL) (Virtual Organ Computer-aided AnaLysis, General Electric Medical Systems, Kretztechnik, Zipf, Austria).

Results: In the DG group, the gastric residue volumes at postprandial 60 and 90 min were significantly higher than those in the healthy group $(\mathrm{P}<0.05)$, and the areas under the receiver operating characteristic (ROC) curve of these parameters were 0.830 and 0.957 , respectively. There were significant differences between the PSG and healthy groups at 60 and $90 \mathrm{~min}$; however, the AUC of gastric residue at $90 \mathrm{~min}(0.955)$ was higher than the AUC at $60 \mathrm{~min}$ (0.697).

Conclusions: Therefore, this study showed that the 3-D US is a powerful tool for assessing gastric emptying and provides a new strategy for diagnosing gastroparesis.

Keywords: Gastric emptying; patients with gastroparesis; three-dimensional ultrasound (3-D US)

Submitted Jul 07, 2021. Accepted for publication Aug 16, 2021.

doi: $10.21037 /$ atm-21-3972

View this article at: https://dx.doi.org/10.21037/atm-21-3972

\section{Introduction}

Gastroparesis is defined by delayed gastric emptying despite the mechanical obstruction of the gastrointestinal tract and presents clinical symptoms including nausea, vomiting, early satiety, postprandial fullness, bloating, and upper abdominal pain $(1,2)$. Due to the aggravating nature of these symptoms, patients with severe forms of the illness can suffer from malnutrition, weight loss, and other manifestations, which seriously affect their life and work. The etiology of gastroparesis is generally divided into 3 categories: postsurgical gastroparesis (PSG), diabetic gastroparesis (DG), and idiopathic gastroparesis (IG) $(3,4)$. Therefore, identifying an accurate diagnostic method for gastroparesis plays a vital role in managing the disease. Motilin, cholecystokinin, gastrin, vasoactive intestinal 
peptide, 5-hydroxytryptamine, somatostatin and brain-gut peptide play an important role in the regulation of digestive tract motor function. Abnormal levels of gastrointestinal hormones and peptides in blood may play a role in the pathogenesis of gastroparesis.

Currently, the diagnostic methods for gastroparesis include the Gastroparesis Cardinal Symptom Index (GCSI) and the evaluation of gastric emptying. The GCSI scale is a retrospective evaluation of patients' symptoms in the 2 weeks before developing the disease. The severity of each symptom is reflected by 0 (not serious) to 5 (very serious), and the GCSI is determined by the average score of the symptoms (5). A higher score indicates greater severity. Many studies used the GCSI to assess the severity of gastroparesis and the effect of the clinical intervention (6-8). However, the GCSI can lead to errors in clinical conditions due to diagnostician subjectivity. Compared to the GCSI, the evaluation of gastric emptying is more objective. Gastric emptying is mainly assessed using scintigraphy, breath testing, wireless motility capsule (WMCs), and ultrasonography. Scintigraphy is a noninvasive, quantitative, and accurate measure. Thus, it is considered the gold standard for clinical diagnosis and experimental research to determine gastric emptying $(9,10)$. Gastroparesis is mainly divided into primary and secondary gastroparesis, in which primary gastroparesis mainly refers to idiopathic gastroparesis of unknown etiology. The diagnosis of paresis needs to meet three conditions, namely, delayed gastric emptying, excluding mechanical obstruction, and the course of disease $>3$ months, but it is generally impossible to judge whether gastric emptying is delayed by clinical symptoms and objective examination is needed. At present, the commonly used clinical methods for delayed gastric emptying include radionuclide scintillation imaging, wireless power capsule technique and carbon breath test, among which radionuclide scintillation imaging is the "gold standard" for clinical diagnosis of delayed gastric emptying.

Nevertheless, the risks of scintigraphy exposing patients to ionizing radiation, particularly children and pregnant women, restricts its use. Scintigraphy also requires specialized, expensive equipment and is, therefore, relatively costly and not readily available. Breath testing, approved by the US Food and Drug Administration (FDA), can replace scintigraphy $(11,12)$. This method is noninvasive and suitable for repeated use, as it does not require special equipment and is relatively cheap. Nevertheless, a few studies revealed that the use of breath testing could present limitations patients with intestinal malabsorption and liver or lung diseases.

Furthermore, ${ }^{13} \mathrm{C}$ spirulina is not always available in China. Similar to scintigraphy and breath testing, WMCs have been approved by the FDA for measuring gastric emptying. Previous studies have shown that the methods of WMCs are highly consistent with traditional methods $(13,14)$. The WMC method is noninvasive, accurate, and has potential for clinical application. However, the WMC method is restricted by its expense and there being few manufacturers of the technology. Ultrasonography is highly practical due to its speed, convenience, suitability for bedside examination, and low cost. In the 1980s, observation of gastric emptying was conducted by ultrasound, and Bateman and collaborators measured total gastric volume by ultrasound (15). Three-dimensional ultrasonography (3-D US) is a recently developed novel investigation technique. This technique is non-invasive and free of ionizing radiation and provides ease in acquiring volume data. 3-D US a powerful aid for accurately measuring the mass and volume of the fetal lungs, thyroid, gallbladder, and other organs (16-18). 3-D US is accurate and convenient for volume measurement, and therefore a potential tool for evaluating gastric volume. In recent years, some studies have assessed the volume of the stomach by utilizing this technology $(19,20)$. However, the number of studies and sample sizes are relatively small, and no diagnostic criteria were obtained. This study aimed to assess the feasibility of evaluating gastric emptying in patients with gastroparesis by 3-D US.

We present the following article in accordance with the STARD reporting checklist (available at https://dx.doi. org/10.21037/atm-21-3972).

\section{Methods}

\section{Study design}

In this prospective study involving the evaluation of gastric emptying in various clinical conditions, the subjects were divided into 3 groups; the healthy group (21 volunteers), the DG group (46 patients), and the PSG group (22 patients). 3-D US was conducted after an overnight fasting period of at least $12 \mathrm{~h}$. After oral administration of $250 \mathrm{~mL}$ contrast agent, postprandial gastric volume scans were performed at Time $=2,30,60$, and $90 \mathrm{~min}$. The volume of the contrast agent in the stomach was then calculated using the virtual organ computer-aided analysis (VOCAL) (Virtual Organ Computer-aided AnaLysis, General Electric Medical 
Systems, Kretztechnik, Zipf, Austria). 3-D US scans were acquired from seated subjects, and during intervals, they were able to stand and move around the room. Before the 3-D US, the study subjects received evaluation using the GCSI, gastroscopy, and upper gastrointestinal radiography. Evaluation of the GCSI and gastroscopy was performed by gastroenterologists (J. Tan and S. Shrestha), and evaluation of the upper gastrointestinal radiography was performed by a radiologist (T. Lu). Evaluation of 3-D US was performed by sonographers (J. Shi and Q. Gao) and J. Shi performed data analysis. When performing the 3-D US, the technicians were blinded to results from the preliminary evaluation.

This study was approved by the Research Ethics Committee of Zhongda Hospital Affiliated to Southeast University [ZDYJLY (2016) 65], and each participant provided written, informed consent before enrollment in the study. All experiments were carried out in accordance with the Declaration of Helsinki (as revised in 2013).

\section{Patients}

The healthy group consisting of 21 healthy volunteers (12 females and 9 males), aged $41.7 \pm 5.8$ years ( $34-50$ years) in the 6 months before the study were without symptoms such as nausea, vomiting, early satiety, postprandial fullness, bloating, or upper abdominal pain, and did not have a history of diabetes, thyroid dysfunction, rheumatic immune disease, gastric or esophageal surgery.

The DG group consisted of 46 diabetic gastroparesis patients ( 24 females and 22 males), aged $54.5 \pm 19.3$ years (25-82 years). The inclusion criteria required subjects to be older than 18 years with a history of diabetes and present with a GCSI >2.3 and delayed gastric emptying confirmed by objective assessment.

The PSG group consisted of 22 postoperative gastroparesis patients (11 females and 11 males), aged $66.2 \pm 8.6$ years ( $48-74$ years). The inclusion criteria required subjects to be older than 18 years with a history of proximal gastric or lower esophageal surgery and without diabetes, and present with a GCSI >2.3 and delayed gastric emptying confirmed by objective assessment.

The objective assessment criteria were as follows: (I) during gastroscopy, where there was no peristalsis or poor peristalsis and gastric fluid retention, but the gastroscope could pass smoothly through the pylorus. (II) During upper gastrointestinal radiography, where there was no peristalsis or poor peristalsis, and the stomach was dilated.
The contrast agent could not pass or could only pass slowly through the pylorus, and there was an absence of mechanical pyloric obstruction.

Patients with the following conditions were excluded: (I) mechanical obstruction of gastric outflow, (II) gastrointestinal motility affected by medication taken within 72 hours of the study, (III) diseases including thyroid dysfunction and rheumatoid arthritis that cause symptoms of gastroparesis, (IV) poor blood glucose control, hyperglycemia (blood glucose level $>200 \mathrm{mg} / \mathrm{dL}$ ), (V) total gastrectomy, (VI) where 3-D we could not probe the remnant stomach due to it being lifted in the thorax, in the PSG group.

\section{Oral contrast agents}

The commercially available oral contrast agent Xinzhang (Huqingyutang Pharmaceutical Technology Co., Ltd., Hangzhou, China) was supplied as a yellow powder, formulated from edible rice, soybean, coix seed xanthan gum, and aspartame with $48 \mathrm{~g} / \mathrm{pack}$ (sugar-free). Each pack of contrast agents was stirred in $500 \mathrm{~mL}$ warm boiled water to make a homogeneous semisolid paste.

\section{3-D US data acquisition and analysis}

The acquisition and volume calculation of 3-D US was performed by a commercially available ultrasound system (Volusion E8; GE Healthcare, New York, USA) and the VOCAL software (GE Healthcare). The 3-D US system was equipped with a convex array volume transducer (GE Healthcare) with a 4-8 $\mathrm{MHz}$ extended operating frequency range and a volume field of view of $90^{\circ} \times 85^{\circ}$.

The transducer detected the maximum section of the stomach. Patients were then required to hold their breath for $2-5 \mathrm{~s}$ to minimize artifacts. Meanwhile, the 3-D model was applied to acquire the long axis, short axis, and coronal plane images of the stomach (Figure 1A). Next, the VOCAL software installed on the ultrasound system was enabled, and the gastric shape curves were manually drawn on the long axis plane at a $15^{\circ}$ rotation angle (Figure $1 B$ ). Finally, after 12 sketches, the VOCAL software automatically generated a 3-D reconstruction image of the stomach and its volume (Figure 1C).

\section{Statistical analysis}

Results were presented as mean \pm standard deviation. The 

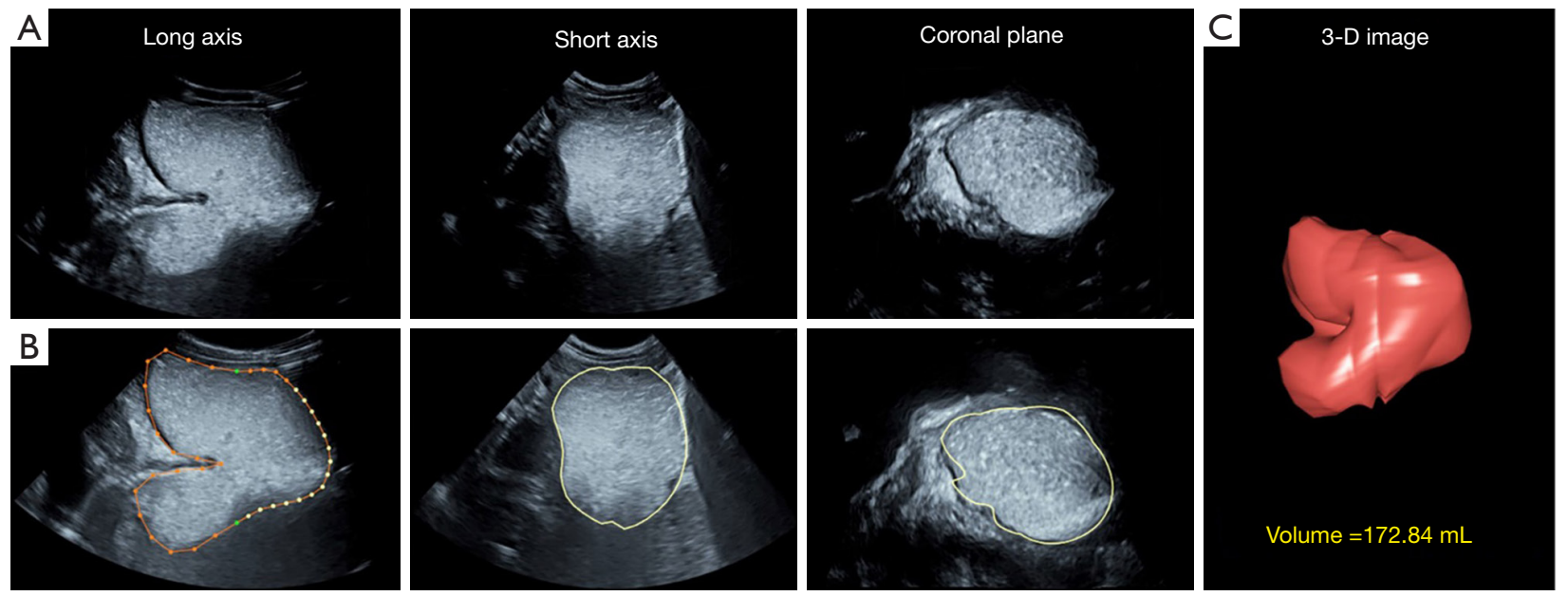

Figure 1 The 3-D US image acquisition and volume analysis. (A) The long axis, short axis, and coronal plane images of the stomach. (B) The gastric shape curves. (C) The 3-D image of the stomach. 3-D US, three-dimensional ultrasonography.

Table 1 Gastric residual volume at $\mathrm{T}_{2}, \mathrm{~T}_{30}, \mathrm{~T}_{60}$, and $\mathrm{T}_{90}$ by 3-D US, and statistical analysis

\begin{tabular}{lcccc}
\hline Variable & $\mathrm{T}_{2}(\mathrm{~mL})$ & $\mathrm{T}_{30}(\mathrm{~mL})$ & $\mathrm{T}_{60}(\mathrm{~mL})$ & $\mathrm{T}_{90}(\mathrm{~mL})$ \\
\hline Healthy group & $203.8 \pm 3.8$ & $111.0 \pm 2.9^{*}$ & $51.0 \pm 3.0^{*}$ & $15.3 \pm 1.2^{*}$ \\
DG group & $193.3 \pm 3.3$ & $119.8 \pm 5.6^{*}$ & $90.8 \pm 5.6^{\star \#}$ & $65.3 \pm 6.5^{\star \#}$ \\
PSG group & $115.9 \pm 12.4^{\#}$ & $81.3 \pm 10.1^{\star \#}$ & $74.6 \pm 8.2^{\#}$ & $64.0 \pm 8.0^{\star \#}$ \\
\hline
\end{tabular}

${ }^{*} \mathrm{P}<0.05$ vs. previous time point including $\mathrm{T}_{30}$ vs. $\mathrm{T}_{2}, \mathrm{~T}_{60}$ vs. $\mathrm{T}_{30}, \mathrm{~T}_{90}$ vs. $\mathrm{T}_{60}$ in the same group. ${ }^{*} \mathrm{P}<0.05$ vs. healthy group including $\mathrm{DG}$ group vs. healthy group, PSG group vs. healthy group at the same time point. 3-D US, three-dimensional ultrasonography; DG, diabetic gastroparesis; PSG, postsurgical gastroparesis; $T_{2}, 2$ minutes after oral administration contrast agents; $T_{30}, 30$ minutes after oral administration contrast agents; $T_{60}, 60$ minutes after oral administration contrast agents; $T_{90}, 2$ minutes after oral administration contrast agents.

intragroup difference of measurement data was analyzed by single factor repeated measurement analysis of variance. An independent sample $t$-test analyzed the intergroup difference in measurement data. The receiver operating characteristic (ROC) curve was used to analyze results and select cut off values. Statistical analyses were performed with SPSS version 19.0 (SPSS Inc., Chicago, IL, USA).

\section{Results}

Measurement of the gastric residual volume at $T_{2}, T_{30}, T_{60}$, and $T_{90}$ in different groups

All subjects in the healthy group and DG group were examined using 3-D US. Twenty-five patients with PSG underwent 3-D US, and 3 of these patients were excluded because the remnant stomach was located in the chest cavity and could not be detected.
The gastric residual volume in the healthy group was significantly different at $\mathrm{T}_{2}, \mathrm{~T}_{30}, \mathrm{~T}_{60}$, and $\mathrm{T}_{90}(203.8 \pm 3.8$, $111.0 \pm 2.9,51.0 \pm 3.0$, and $15.3 \pm 1.2 \mathrm{~mL})(\mathrm{P}<0.05)$. A significant difference existed in gastric residual volume in the DG group at $\mathrm{T}_{2}, \mathrm{~T}_{30}, \mathrm{~T}_{60}$, and $\mathrm{T}_{90}(193.3 \pm 3.3,119.8 \pm 5.6,90.8 \pm 5.6$, and $65.3 \pm 6.5 \mathrm{~mL})(\mathrm{P}<0.05)$. The gastric residual volume in the PSG group was significantly different between $\mathrm{T}_{2}$ $(115.9 \pm 12.4 \mathrm{~mL})$ and $\mathrm{T}_{30}(81.3 \pm 10.1 \mathrm{~mL})(\mathrm{P}<0.05)$, and between $\mathrm{T}_{60}(74.6 \pm 8.2 \mathrm{~mL})$ and $\mathrm{T}_{90}(64.0 \pm 8.0 \mathrm{~mL})(\mathrm{P}<0.05)$. However, the gastric residual volume in the PSG group was not significantly different between $\mathrm{T}_{30}$ and $\mathrm{T}_{60}(\mathrm{P}>0.05)$. The results are shown in Table 1.

\section{Comparison of gastric residual volume in different groups}

There was a significant difference in gastric residual volume measured by the 3-D US between the healthy group and 


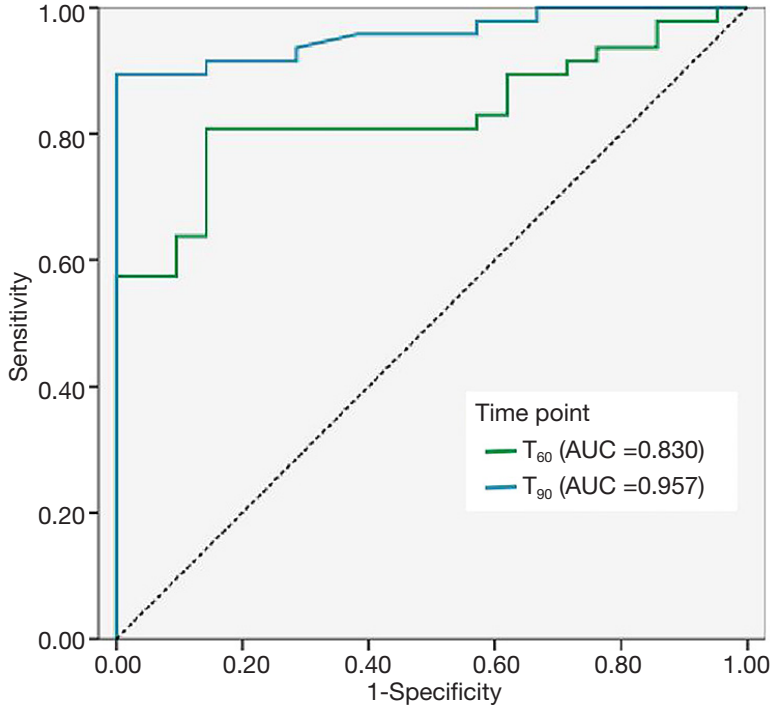

Figure 2 The ROC curve for $D G$ at $T_{60}$ and $T_{90}$. ROC, receiver operating characteristic; DG, diabetic gastroparesis; AUC, the area under the ROC curve; $\mathrm{T}_{60}, 60$ minutes after oral administration contrast agents; $\mathrm{T}_{90}, 2$ minutes after orally administered contrast agents.

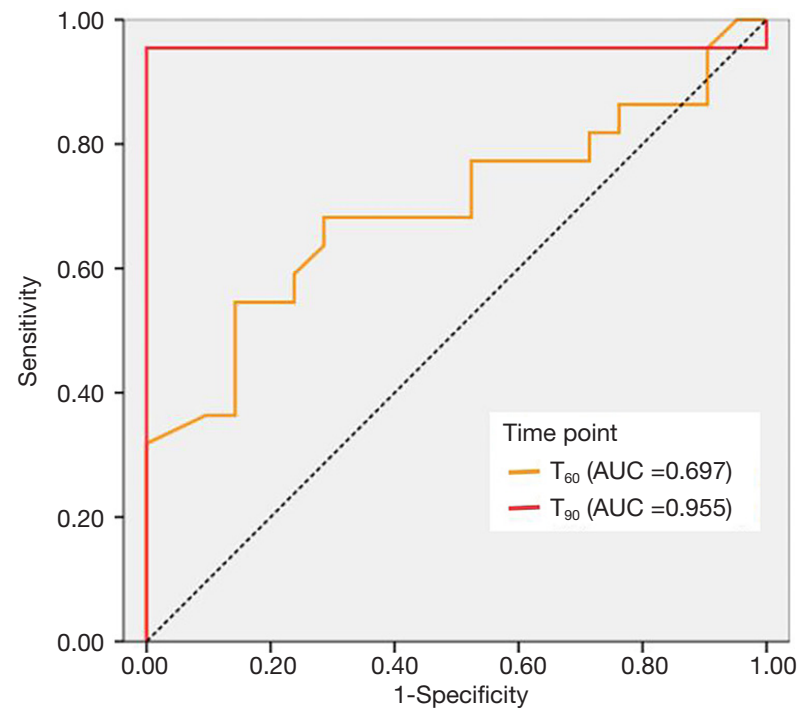

Figure 3 The ROC curve for PSG at $T_{60}$ and $T_{90}$. ROC, receiver operating characteristic; $\mathrm{PSG}$, postsurgical gastroparesis; AUC, the area under the ROC curve; $\mathrm{T}_{60}, 60$ minutes after orally administered contrast agents; $\mathrm{T}_{90}, 2$ minutes after orally administered contrast agents.

the DG group at $\mathrm{T}_{60}$ and $\mathrm{T}_{90}(51.0 \pm 3.0$ vs. $90.8 \pm 5.6 \mathrm{~mL}$, $15.3 \pm 1.2$ vs. $65.3 \pm 6.5 \mathrm{~mL})(\mathrm{P}<0.05)$, respectively. There was a significant difference in gastric residual volume between the healthy group and the PSG group at $\mathrm{T}_{2}, \mathrm{~T}_{30}, \mathrm{~T}_{60}$, and $\mathrm{T}_{90}$ (203.8 83.8 vs. $115.9 \pm 12.4 \mathrm{~mL}, 111.0 \pm 2.9$ vs. $81.3 \pm 10.1 \mathrm{~mL}$, $51.0 \pm 3.0$ vs. $74.6 \pm 8.2 \mathrm{~mL}$, and $15.3 \pm 1.2$ vs. $64.0 \pm 8.0 \mathrm{~mL}$ ), respectively $(\mathrm{P}<0.05)$. The results are shown in Table 1 .

\section{Evaluation of gastroparesis by 3-D US}

In the DG group, the gastric residual volumes at $\mathrm{T}_{60}$ and $\mathrm{T}_{90}$ were statistically significant for evaluating gastroparesis $(\mathrm{P}<0.05)$. The ROC curve for these 2 variables was applied to assess DG. The area under the ROC curve of the gastric residual volume at $\mathrm{T}_{60}$ was 0.830 , and the cut-off value was $62.7 \mathrm{~mL}$ with $81 \%$ sensitivity and $86 \%$ specificity; the area under the ROC curve of gastric residual volume at $\mathrm{T}_{90}$ was 0.957 , and the cut-off value was $23.6 \mathrm{~mL}$ with $89 \%$ sensitivity and $99 \%$ specificity. The results are shown in Figure 2.

The gastric residuals at $T_{60}$ and $T_{90 \text { can }}$ effectively evaluate gastric emptying of PSG $(\mathrm{P}<0.05)$. Therefore, the ROC curves of these 2 indicators were analyzed to evaluate PSG. As shown in Figure 3, the area under the ROC curve of the gastric residual volume at $T_{90}(0.955)$ was greater than at $\mathrm{T}_{60}(0.697)$. Both the sensitivity (95\%) and specificity (99\%) cut-off value of $25.2 \mathrm{~mL}$ at $\mathrm{T}_{90}$ were higher than the sensitivity (55\%) and specificity (86\%) cut-off value of $61.0 \mathrm{~mL}$ at $\mathrm{T}_{60}$.

\section{Discussion}

Since the symptoms of gastroparesis are nonspecific, delayed gastric emptation occurs in $25-35 \%$ of patients with dyspepsia. Because of the poor correlation between gastric emptying time, symptom relief and the efficacy of prokinetic drugs in patients with gastroparesis, improving delayed gastric emptying is not the end point of gastroparesis treatment. At present, the clinical treatment of gastroparesis aims to improve the symptoms and improve the quality of life of patients, to correct malnutrition, reduce symptoms, aiming at the etiological treatment as the principle, the main methods include diet adjustment, drug treatment, non-drug treatment. The impaired gastric mobility caused by gastrointestinal diseases can lead to delayed gastric emptying. Hence, research on gastric emptying is a topic of focus for physicians and radiologists. Various techniques are applied to measure gastric emptying, including scintigraphy, upper gastrointestinal contrasting, magnetic resonance imaging, ultrasonography, and breath testing. Many studies have reported that ultrasonography is highly consistent with 
the other measures for evaluating gastric emptying (20-23). The main ultrasonic methods include the 2-D ultrasound and 3-D ultrasound gastric volume methods to measure the whole stomach volume, gastric antrum volume, and gastric antrum area. To assess gastric emptying, the area or volume of the stomach or antrum, which was hypothesized to have a regular shape, was calculated using 2-D ultrasonography (23-25). However, the shape of the stomach can be irregular, which may lead to measuring errors using 2-D ultrasonography. In contrast, the 3-D US can accurately measure gastric volume and is not restricted by object shape because it adopts a matrix transducer. In this study, 3-D US was used to explore the gastric residues of patients and exhibited outstanding performance.

In many past studies, patients were given experimental meals with different ingredients (such as scintigraphy standard meals or high-nutrient liquid) and different dosages $(350 \mathrm{~mL}, 500 \mathrm{~mL}$, etc.), which led to different results $(19,21,26)$. In the present study, we used the identical test meals with identical dosages, a commercially available oral contrast agent containing the same ingredients in each pack. After using identical preparation methods, the semisolid paste-like contrast agent showed homogeneous high echo in the ultrasound image and a clear boundary with the stomach wall, which was more conducive to detecting the gastric residual amount. Some patients with gastroparesis cannot consume high amounts of food or consume food quickly without experiencing extreme discomforts, such as abdominal pain and vomiting. To ensure that the study could be carried out without interruption and for the study subjects to feel comfortable, we used a contrasting dose of $250 \mathrm{~mL}$ and 2 minutes after patients consumed the test meal as the starting point, based on the pre-test experience. Gastric emptying in patients is affected by their posture. In contrast to former studies, patients were tested in a seated position in this study. The potential advantages were as follows: (I) the posture is common in daily life, ensuring more realistic results; (II) stomach gas is located at the fundus, thus reducing interference of stomach gas on ultrasound images; (III) the contrast agent was concentrated in the antrum and the distal stomach, which was conducive to the acquisition of 3-D US images.

Various factors impact gastric emptying; including gastric accommodation, the pressure difference between the proximal and distal stomach, the pressure gradient between the antrum and duodenum, and swallowing movement (27). In the present study, after the patient was administered the $250 \mathrm{~mL}$ test meal, the measured gastric volume was less than $250 \mathrm{~mL}$ at the starting point time $\left(\mathrm{T}_{2}\right)$, especially in the PSG group $(115.0 \mathrm{~mL})$. The possible reasons could be that due to irritation caused by the test meal and the internal pressure difference, part of the contrast agent, had been emptied before the starting point; or because in the PSG group, part of the stomach was located in the chest, which could not be detected by ultrasound. The measured data only included the stomach located in the abdominal cavity.

At present, the parameters for determining gastric emptying are various gastric emptying times, including $1 / 4$, $1 / 2,3 / 4$, and full emptying time $(23,28)$. These indicators are estimated by plotting the trend of gastric emptying. Consequently, the method of measuring gastric emptying using emptying time is not useful in clinical practice due to its inconvenience and fallibility. In this study, the number of gastric residues at various time points was directly evaluated gastric emptying, and the appropriate values were sought to help diagnose delayed gastric emptying.

Previous investigations have reported that the 3-D US is highly effective in measuring the stomach volume of healthy volunteers . In the present work, patients with DG and PSG were included, providing greater relevance to clinicians. DG $(26,29)$ is caused by the reduction of autonomic neuropathy and damaged interstitial cells of Cajal (ICC). PSG usually occurs following chest or upper abdominal surgery and is caused by impairment to the vagus nerve and fold fundus. There is a difference in gastric volume among 2 patient groups. In this study, the gastric residue in 3 groups of patients gradually decreased with increasing time. As shown in Figure 4, the trend of decline is markedly different. In the healthy group, the descent rate of gastric residue occurs rapidly from 2 to $90 \mathrm{~min}$. However, in the DG and PSG groups, the rate is slow, at 2 to $30 \mathrm{~min}$. The rate further slows after $30 \mathrm{~min}$. Therefore, taking the trend into account plays a vital role in administering medicine and high-nutrition meals.

Additionally, the ROC curve analyzed the meaningful variables, which was useful for the diagnosis of noninvasive gastroparesis. The gastric residue in the DG group was significantly higher than that in the healthy group at 60 and $90 \mathrm{~min}$. Both the ROC cutoff point and the area under the ROC curve (AUC) demonstrated high performance at 60 and 90 min. Interestingly, the AUC was 0.955 in the PSG group at $90 \mathrm{~min}$, indicating this point can be considered a high accuracy reference. The cut-off value, sensitivity, and specificity was $25 \mathrm{~mL}, 90 \%$, and $98 \%$. However, since the sample size was small, further research is required to verify 


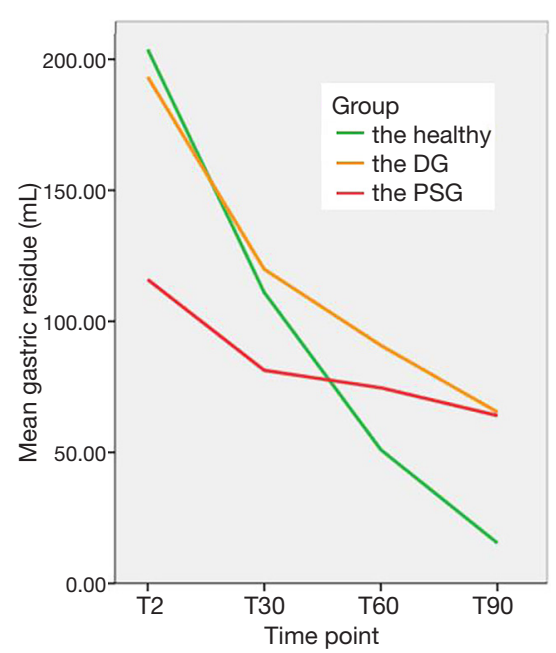

Figure 4 The trend of gastric residue in 3 groups at different time points. DG, diabetic gastroparesis; PSG, postsurgical gastroparesis.

the accuracy of these thresholds as diagnostic criteria.

In this study, 3-D US was used to evaluate the gastric emptying function of subjects in 3 groups (healthy group, DG group, PSG group) at various time points $\left(T_{2}, T_{30}, T_{60}\right.$, $\mathrm{T}_{90}$ ) following oral administration of $250 \mathrm{ml}$ gastrointestinal contrast agent. Limitations of this study include the long measurement period $(30 \mathrm{~min})$, which might have resulted in missing the optimum value for the assessment of delayed gastric emptying, and that the sample size was small, possibly indicative of sampling errors.

In conclusion, 3-D US can evaluate gastric emptying by measuring gastric residue volume and can be useful for the objective diagnosis of gastroparesis.

\section{Acknowledgments}

Funding: This work was supported by grants from the National Natural Science Foundation (No. 81600429) and the Nanjing Health Science and Technology Development Fund (No. YKK18250).

\section{Footnote}

Reporting Checklist: The authors have completed the STARD reporting checklist. Available at https://dx.doi. org/10.21037/atm-21-3972

Data Sharing Statement: Available at https://dx.doi. org/10.21037/atm-21-3972
Conflicts of Interest: All authors have completed the ICMJE uniform disclosure form (available at https://dx.doi. org/10.21037/atm-21-3972). The authors have no conflicts of interest to declare.

Ethical Statement: The authors are accountable for all aspects of the work in ensuring that questions related to the accuracy or integrity of any part of the work are appropriately investigated and resolved. This study was approved by the Research Ethics Committee of Zhongda Hospital Affiliated to Southeast University [ZDYJLY (2016) 65], and each participant provided written, informed consent before enrollment in the study. All experiments were carried out in accordance with the Declaration of Helsinki (as revised in 2013).

Open Access Statement: This is an Open Access article distributed in accordance with the Creative Commons Attribution-NonCommercial-NoDerivs 4.0 International License (CC BY-NC-ND 4.0), which permits the noncommercial replication and distribution of the article with the strict proviso that no changes or edits are made and the original work is properly cited (including links to both the formal publication through the relevant DOI and the license). See: https://creativecommons.org/licenses/by-nc-nd/4.0/.

\section{References}

1. Camilleri M, Parkman HP, Shafi MA, et al. Clinical guideline: management of gastroparesis. Am J Gastroenterol 2013;108:18-37; quiz 38.

2. Camilleri M, Chedid V, Ford AC, et al. Gastroparesis. Nat Rev Dis Primers 2018;4:41.

3. Jalleh R, Marathe CS, Rayner CK, et al. Diabetic Gastroparesis and Glycaemic Control. Curr Diab Rep 2019;19:153.

4. Tack J, Carbone F, Rotondo A. Gastroparesis. Curr Opin Gastroenterol 2015;31:499-505.

5. Revicki DA, Rentz AM, Dubois D, et al. Development and validation of a patient-assessed gastroparesis symptom severity measure: the Gastroparesis Cardinal Symptom Index. Aliment Pharmacol Ther 2003;18:141-50.

6. Barshop K, Staller K, Semler J, et al. Duodenal rather than antral motility contractile parameters correlate with symptom severity in gastroparesis patients. Neurogastroenterol Motil 2015;27:339-46.

7. Ejskjaer N, Dimcevski G, Wo J, et al. Safety and efficacy of 
ghrelin agonist TZP-101 in relieving symptoms in patients with diabetic gastroparesis: a randomized, placebo-controlled study. Neurogastroenterol Motil 2010;22:1069-e281.

8. Gonzalez JM, Benezech A, Vitton V, et al. G-POEM with antro-pyloromyotomy for the treatment of refractory gastroparesis: mid-term follow-up and factors predicting outcome. Aliment Pharmacol Ther 2017;46:364-70.

9. Abell TL, Camilleri M, Donohoe K, et al. Consensus recommendations for gastric emptying scintigraphy: a joint report of the American Neurogastroenterology and Motility Society and the Society of Nuclear Medicine. Am J Gastroenterol 2008;103:753-63.

10. Orthey P, Yu D, Van Natta ML, et al. Intragastric Meal Distribution During Gastric Emptying Scintigraphy for Assessment of Fundic Accommodation: Correlation with Symptoms of Gastroparesis. J Nucl Med 2018;59:691-7.

11. Odunsi ST, Camilleri M, Szarka LA, et al. Optimizing analysis of stable isotope breath tests to estimate gastric emptying of solids. Neurogastroenterol Motil 2009;21:706-e38.

12. Szarka LA, Camilleri M, Vella A, et al. A stable isotope breath test with a standard meal for abnormal gastric emptying of solids in the clinic and in research. Clin Gastroenterol Hepatol 2008;6:635-643.e1.

13. Kloetzer L, Chey WD, McCallum RW, et al. Motility of the antroduodenum in healthy and gastroparetics characterized by wireless motility capsule. Neurogastroenterol Motil 2010;22:527-33, e117.

14. Maqbool S, Parkman HP, Friedenberg FK. Wireless capsule motility: comparison of the SmartPill GI monitoring system with scintigraphy for measuring whole gut transit. Dig Dis Sci 2009;54:2167-74.

15. Bateman DN, Whittingham TA. Measurement of gastric emptying by real-time ultrasound. Gut 1982;23:524-7.

16. Li WB, Zhang B, Zhu QL, et al. Comparison between Thin-Slice 3-D Volumetric Ultrasound and Conventional Ultrasound in the Differentiation of Benign and Malignant Thyroid Lesions. Ultrasound Med Biol 2015;41:3096-101.

17. Serra C, Pallotti F, Bortolotti M, et al. A New Reliable Method for Evaluating Gallbladder Dynamics: The 3-Dimensional Sonographic Examination. J Ultrasound Med 2016;35:297-304.

18. Wang SS, Tian XY, Yan HW, et al. Prenatal assessment of pulmonary maturity on 3-D ultrasound. J Obstet Gynaecol Res 2016;42:1086-93.

19. Liu Z, Liu Z, Li Y, et al. Evaluation of Gastric Emptying by Transabdominal Ultrasound after Oral Administration of Semisolid Cellulose-Based Gastric Ultrasound Contrast
Agents. Ultrasound Med Biol 2018;44:2183-8.

20. Stevens JE, Gilja OH, Gentilcore D, et al. Measurement of gastric emptying of a high-nutrient liquid by $3 \mathrm{D}$ ultrasonography in diabetic gastroparesis. Neurogastroenterol Motil 2011;23:220-5, e113-4.

21. Buisman WJ, Mauritz FA, Westerhuis WE, et al. Evaluation of Gastric Volumes: Comparison of 3-D Ultrasound and Magnetic Resonance Imaging. Ultrasound Med Biol 2016;42:1423-30.

22. Gentilcore D, Hausken T, Horowitz M, et al. Measurements of gastric emptying of low- and highnutrient liquids using 3D ultrasonography and scintigraphy in healthy subjects. Neurogastroenterol Motil 2006;18:1062-8.

23. Shen HL, Yang SP, Hong LW, et al. Evaluation of gastric emptying in diabetic gastropathy by an ultrasonic whole stomach cylinder method. Ultrasound Med Biol 2014;40:1998-2003.

24. Bouvet L, Bellier N, Gagey-Riegel AC, et al. Ultrasound assessment of the prevalence of increased gastric contents and volume in elective pediatric patients: A prospective cohort study. Paediatr Anaesth 2018;28:906-13.

25. Bouvet L, Zieleskiewicz L, Loubradou E, et al. Reliability of gastric suctioning compared with ultrasound assessment of residual gastric volume: a prospective multicentre cohort study. Anaesthesia 2020;75:323-30.

26. Muresan C, Surdea Blaga T, Muresan L, et al. Abdominal Ultrasound for the Evaluation of Gastric Emptying Revisited. J Gastrointestin Liver Dis 2015;24:329-38.

27. Ikeo K, Oshima T, Sei H, et al. Acotiamide improves stress-induced impaired gastric accommodation. Neurogastroenterol Motil 2017. doi: 10.1111/nmo.12991.

28. Chiu YC, Kuo MC, Rayner CK, et al. Decreased gastric motility in type II diabetic patients. Biomed Res Int 2014;2014:894087.

29. Buisman WJ, van Herwaarden-Lindeboom MY, Mauritz FA, et al. Validation of a Novel 3-Dimensional Sonographic Method for Assessing Gastric Accommodation in Healthy Adults. J Ultrasound Med 2016;35:1411-8.

(English Language Editors: B. Maizey and J. Chapnick)

Cite this article as: Shi J, Shen H, Gao Q, Mulmi Shrestha S, Tan J, Lu T, Yang B. Evaluation of gastric emptying in patients with gastroparesis by three-dimensional ultrasound. Ann Transl Med 2021;9(16):1343. doi: 10.21037/atm-21-3972 